\title{
Logic, Ontological Neutrality, and the Law of Non-Contradiction
}

\author{
Achille C. Varzi \\ Department of Philosophy, Columbia University, New York
}

[Final version published in Elena Ficara (ed.), Contradictions. Logic, History, Actuality, Berlin: De Gruyter, 2014, pp. 53-80]

\begin{abstract}
As a general theory of reasoning — and as a theory of what holds true under every possible circumstance-logic is supposed to be ontologically neutral. It ought to have nothing to do with questions concerning what there is, or whether there is anything at all. It is for this reason that traditional Aristotelian logic, with its tacit existential presuppositions, was eventually deemed inadequate as a canon of pure logic. And it is for this reason that modern quantification theory, too, with its residue of existentially loaded theorems and inferential patterns, has been claimed to suffer from a defect of logical purity. The law of non-contradiction rules out certain circumstances as impossible-circumstances in which a statement is both true and false, or perhaps circumstances where something both is and is not the case. Is this to be regarded as a further ontological bias? If so, what does it mean to forego such a bias in the interest of greater neutrality - and ought we to do so?
\end{abstract}

\section{Logic in the Locked Room}

As a general theory of reasoning, and especially as a theory of what is true no matter what is the case (or in every "possible world"), logic is supposed to be ontologically neutral. It should be free from any metaphysical presuppositions. It ought to have nothing substantive to say concerning what there is, or whether there is anything at all. For Kant, it is "pure" and "a priori". "For Russell, it doesn't deal with "mere accidents". ${ }^{2}$ For Gödel, it is "a science prior to all other". 3

This conception of logic may be illustrated with the help of the "locked room" metaphor. ${ }^{4}$ Logicians must pretend to be locked in a dark, windowless room, and to know nothing about the world outside. When confronted with a statement, they must try to evaluate it exclusively on the basis of their linguistic competence. If they can establish that it is true, then the statement is logically true. And if they can establish that the statement is true on the assumption that certain other statements are true, then the corresponding argument is logically valid. Logi-

${ }^{1}$ Critique of Pure Reason (e.g., A53/B77, A54/B78, A131/B170) and elsewhere.

${ }^{2}$ Russell (1919b), p. 205.

${ }^{3}$ Gödel (1944), p. 125.

${ }^{4}$ From Bencivenga (1999), pp. 6-7. 
cal truth and validity are based on how our language works, and on our ability to keep track of the fixed meaning of certain syncategorematic expressions such as connectives and quantifiers. They do not depend on what extralinguistic reality might look like.

It is precisely because it didn't measure up to this conception that traditional Aristotelian logic has eventually been deemed inadequate as a canon of pure logical reasoning. The relations among categorical statements that make up the traditional Square of Opposition (Fig. 1) were supposed to determine valid patterns of inference. ${ }^{5}$ Yet most of them really rest on implicit existential assumptions concerning the extension of the subject term, $S$, and should not, therefore, count as valid as a matter of pure logic. ${ }^{6}$

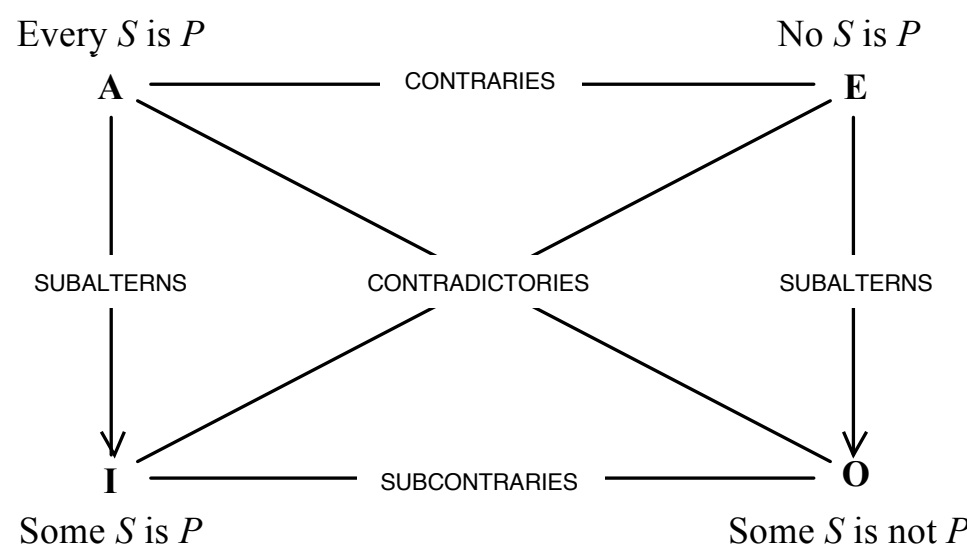

Fig. 1 - The traditional Square of Opposition

For example, the inference from an A-form universal statement to its I-form particular subaltern,

(1) Every $S$ is $P$.

$\therefore$ Some $S$ is $P$.

depends on the existence of at least one $S$, since in an $S$-less world the conclusion would be false whereas the premise would be true, albeit vacuously. Of course, one could just reject the notion of vacuous universal truth by insisting that the nonemptiness of the subject term is presupposed in every A-form statement. After all, most ordinary-language speakers share that intuition. However, such a move

${ }^{5}$ The traditional Square emerges from Aristotle's remarks in De Interpretatione 67 (17b.17-26) and in Prior Analytics I.2 (25a1-25).

${ }^{6}$ For a history of the issue, see e.g. Church (1965). 
would leave us with a logical theory that cannot distinguish between those arguments whose validity depends on the presupposition, such as instances of (1), and those that do not, such as instances of

(2) Every $S$ is $P$.

$\therefore$ It is not the case that some $S$ is not $P{ }^{7}$

Besides, the move would still not suffice to salvage the traditional Square. For, if ' $S$ ' is indeed an empty term, then certainly the I-form statement, 'Some $S$ is $P$ ', must be false. But then its contradictory $\mathbf{E}$-form, 'No $S$ is $P$ ', must be true, and that would imply the truth of the subaltern $\mathbf{O}$-form, 'Some $S$ is not $P$ '-contradicting the assumption that there are no $S \mathrm{~s}$ to begin with. ${ }^{8}$

Modern quantification theory, as rooted in the work of Frege, Russell, and Whitehead, ${ }^{9}$ is much better in this respect, as it is free from all the existential commitments of Aristotelian logic. The modern interpretation of the Square of Opposition condones only the two relations of contradictoriness - along the diagonalsrejecting all other relations as strictly speaking invalid:

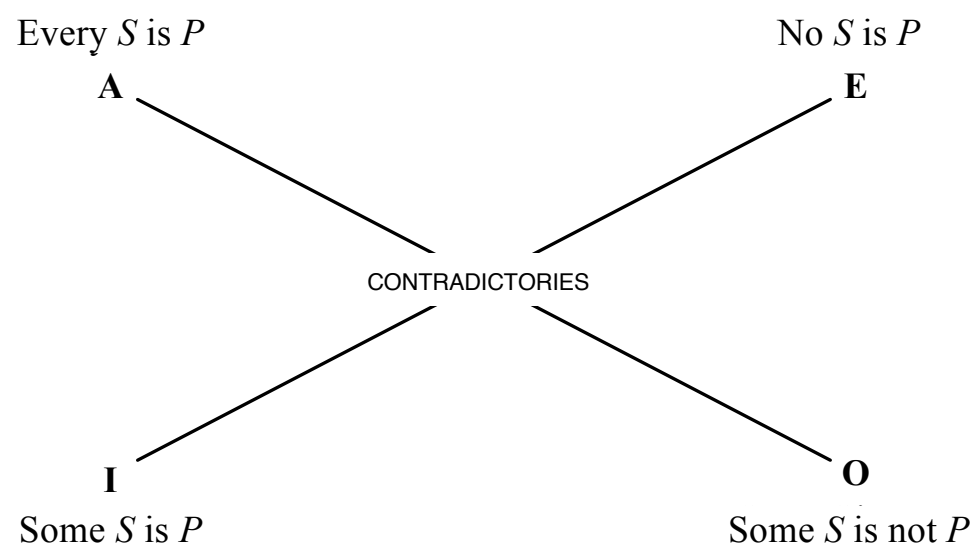

Fig. 2 - The revised Square of Opposition

In order to permit, for instance, an inference of subalternation, the modern logician requires that an additional premise be added, making explicit the existential assumption that in (1) was implicit:

${ }^{7}$ This complaint goes back to Lambert (1967), p. 134.

${ }^{8}$ This reasoning goes back to Kneale and Kneale (1962), pp. 55-60. It should be noted that on some translations of De Interpretatione the argument does not go through, since the $\mathbf{O}$-form is rendered as 'Not every $S$ is $P$ '. See Wedin (1990).

${ }^{9}$ Frege (1893/1903) and Whitehead and Russell (1910/1913). 
(1') Every $S$ is $P$.

There exists some $S$.

$\therefore$ Some $S$ is $P$.

As it turns out, however, quantification theory cannot claim full ontological neutrality, either. For while it blocks the problematic inferences of Aristotelian logic, it still sanctions as valid inferential patters that are, on the face of it, ontologically committing, as in (3) and (4):

(3) Everything is $P$.

$\therefore$ Something is $P$.

(4) Everything is $P$.

$\therefore a$ is $P$.

Obviously, the inference in (3) rests on the implicit assumption that something must exist, since in an empty world the conclusion would be false whereas the premise would be (vacuously) true, while the inference in (4) rests on the specific assumption that $a$ exists, i.e., that ' $a$ ' denotes something. Indeed, modern quantification theory also sanctions as logically true statements that carry explicit existential import, such as

(5) Something is either $P$ or not $P$.

(6) Something is self-identical.

Even the following comes out as a logical truth:

(7) Something exists.

and to the extent that ' $a$ ' is treated as a genuine singular term, so does

(8) $a$ exists.

One can tinker with the pieces, alter the reading of the quantifiers, make room for mere possibilia, get rid of singular terms, etc. ${ }^{10}$ But all this just confirms the problem. As Russell himself acknowledged a few years after the publication of Principia Mathematica, the provability of such existential theorems is a "defect in logical purity". 11

${ }^{10}$ For example, Russell's (1905) theory of descriptions provides the resources for disposing of (8) by rewriting it as 'There exists exactly one thing that $a$-izes', which is not a theorem of quantification theory. (See Quine 1948.)

${ }^{11}$ Russell (1919a), p. 203. See also Russell (1919b), p. 205. In both cases, Russell was referring explicitly to (7). 
Free logic, as rooted in the more recent work of Leonard, Lambert, Hintikka and others, ${ }^{12}$ is so called precisely because it is "free" from the existential presuppositions that are responsible for such remnants of logical impurity. It allows, not only for empty general terms, but also for non-denoting singular terms, and it does not rule out the possibility that the domain of quantification be empty, i.e., that there exist nothing at all. ${ }^{13}$ Again, the remedy lies in revising the problematic inferential patterns by making the relevant existential presuppositions explicit. For example, (3) and (4) become

(3') Everything is P.

Something exists.

$\therefore$ Something is $\mathrm{P}$.

(4') Everything is P.

$a$ exists.

$\therefore a$ is $\mathrm{P}$.

Once this is done, the contentious existential claims in (5)-(8) are no longer provable, either, and free logicians can fairly claim to have achieved greater purity in the spirit of the "locked room" metaphor.

Is this the end of the story? Is free logic completely pure, universal, ontologically neutral? Today this is still an open question, as it is an open and controversial question whether there is in fact any logical theory that can claim the honor. Among other things, it may be observed that free logic shares with classical quantification theory the Square of Opposition in figure 2, which in turn is meant to retain the uncompromising patterns of inference of the traditional Square of figure 1. But are the surviving relations of contradictoriness truly neutral from an ontological perspective? If, for example, it were possible for something to be neither $P$ nor not $P$, then the A-form statement 'Every $S$ is $P$ ' and the corresponding $\mathbf{O}$ form statement 'Some $S$ is not $P$ ' could both be false simultaneously. And if it were possible for there to be something that is both $P$ and not $P$, then those statements could be both true. More generally, from traditional Aristotelian logic through modern quantification theory all the way to free logic, the following two principles are assumed in the background (for any predicate ' $P$ '):

${ }^{12}$ See e.g. Leonard (1956), Hintikka (1959), and Lambert (1967). For a survey of free logic, see Bencivenga (1986) and Lehmann (2002).

${ }^{13}$ Strictly speaking, logics admitting the empty domain of quantification are called "inclusive". While an inclusive logic for a language whose non-logical vocabulary contains singular terms must be free, a free logic need not be inclusive. (The first inclusive logic_-without singular terms — goes back to Jaśkowski 1934.) 
(9) Everything is either $P$ or not $P$.

(10) Nothing is both $P$ and not $P$.

Yet one might object that these principles - the law of excluded middle and the law of non-contradiction, on some terminology - betray a conception of possibility that is ultimately rooted in metaphysics, not in the linguistic competence that should guide our work in the locked room. It is the business of metaphysics, not of logic, to legislate on whether an object can ever be indeterminate, or overdeterminate, with respect to any given property or condition $P$. And if this objection is granted, then clearly the alleged neutrality of free logic, as of any other theory endorsing (9) or (10), founders.

In fact, (9) has been especially challenged over the years, though often in terms that leave the question open. For example, it has frequently been pointed out that vagueness is a natural source of counterexamples to the law of excluded middle. ${ }^{14}$ To the extent that the extension of a predicate ' $P$ ' may not be fully precise, it may admit of borderline cases that do not comply with (9) - things that are neither definitely $P$ (i.e., falling inside the extension) nor definitely not $P$ (i.e., falling outside). Yet it might be replied that cases of this sort do not necessarily affect the generality of (9). They may induce a violation of the semantic (metalinguistic) principle of bivalence, namely

(11) Every statement is either true or false,

but that need not entail a failure of the law of excluded middle as such. ${ }^{15}$ In order to have a genuine counterexample to (9), we need to make room for genuine ontological, de re indeterminacy, and according to a certain line of reasoning, that is not a coherent option. ${ }^{16}$ As Russell famously put it, to claim that linguistic vagueness is a sign of ontic indeterminacy is to incur a "fallacy of verbalism". 17

It is indeed an open question whether this sort of response is acceptable from the present perspective, i.e., whether it does not already betray a metaphysical stance that ought not to be built into the laws of logic. ${ }^{18}$ More importantly, it is an

${ }^{14}$ The point goes back to Frege (1893/1903), vol. 2, §56, though Frege himself saw it as a reason to require that all vagueness be banned from the scope of logical theorizing.

${ }^{15}$ This is the gist, for instance, of Fine's (1975) supervaluational account of vagueness. For the argument that the excluded middle does entail bivalence (so that failure of the latter would entail failure of the former), see Williamson (1992), esp. pp. 145-146.

${ }^{16}$ See e.g. Evans (1978), Salmon (1982), pp. 243-246, and Pelletier (1989).

${ }^{17}$ Russell (1923), p. 85.

${ }^{18}$ See Williams (2008) and Hyde (2008) for a survey of some views on this question. For my own thoughts, I refer to Varzi (2001). I'll come back to this below, too. 
open, deep question whether there may be other legitimate sources of ontic indeterminacy over and above vagueness, hence other legitimate reasons to doubt the ontological neutrality of (9). I'm not, however, going to delve into such questions here, at least not in their own right, as they would take us to far afield. Rather, my purpose is to focus on (10) and consider the parallel question of whether the law of non-contradiction, too, is open to the charge of infringing the expected on-

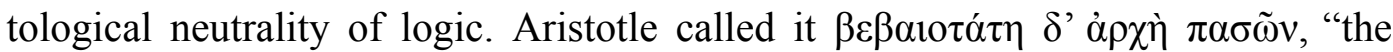
most certain principle of all", ${ }^{19}$ and it is fair to say that this characterization has survived more or less intact until our days. Indeed, Aristotle himself viewed the incompatibility between contradictories as the most fundamental form of opposition, thus predicting the destiny of the traditional Square in our times. ${ }^{20}$ Nonetheless, even this principle has occasionally been questioned on various grounds, were it only to exhibit its status as an "unshakable dogma" (Łukasiewicz's phrase ${ }^{21}$ ) of Western thought. The development of paraconsistent logic, as grounded in the work of Vasil'év, Jaśkowski, Asenjo, da Costa, Priest, and others, ${ }^{22}$ bears witness to the determination with which the project of resisting the dogma has actually been pursued in the twentieth century. In many cases, the original motivations had little to do with the quest for a pure, universally applicable, ontologically neutral theory: from the liar paradox and the set-theoretic antinomies to belief revision, relevant implication, automated reasoning, and beyond. All of these are areas which, as Priest puts it, lie "at the limits of thought and language", ${ }^{23}$ but it is not obvious that they provide good evidence for the possibility of genuine de re counterexamples to (10), as opposed to evidence against the semantic principle of contravalence:

(12) No statement is both true and false.

Even the rise of dialetheism in recent times - the view according to which, not only could there be, but there are violations of the law of non-contradiction-is in principle subject to this worry, ${ }^{24}$ and the step from semantics to ontology is as vul-

${ }^{19}$ Metaphysics, IV.3 (1005b11-12); W. D. Ross's translation.

${ }^{20}$ Metaphysics, IV.5 (1008a35-b12).

${ }^{21}$ Łukasiewicz (1910a), p. 87, retained in the (1910b) summary, p. 37.

${ }^{22}$ See e.g. Vasil'év (1912), Jaśkowski (1948), Asenjo (1966), da Costa (1974), and Priest (1979). For a survey of paraconsistent logic, see Priest (2002).

${ }^{23}$ Priest (1995). See also Priest (1987).

${ }^{24}$ After all, the term 'dialetheism' comes from di-aletheia, a two-way truth. See Priest and Routley (1989a), p. xx. It is worth noting, however, that Priest takes (12) to express the law of non-contradiction itself; see e.g. Priest (1998), p. 416. 
nerable to the "fallacy of verbalism" in this case as it is in the case of putative failures of the excluded middle. Still, all of this demands close scrutiny. I'll leave it to others to assess the pros and cons of paraconsistent logic and dialetheism vis-à-vis the many motivations that led to their development. The specific question I'm interested in, here, is whether and to what extent the pressure to relinquish such a fundamental principle as (10) may be viewed as an expression of the general need to develop logical theories in the spirit of the "locked room" conception mentioned at the beginning. Does (10) betray a genuine ontological bias? If so, what does it mean to forego such a bias in the interest of even greater neutrality?

\section{A Big Deal}

It is, in fact, not quite accurate to frame the issue exclusively in terms of the principle of non-contradiction, as formulated in (10). Before looking at the details, however, there is a general point that needs to be clarified. For if the worry is that (10) delivers a notion of validity that is ontologically biased, one might wonder whether the worry is well grounded at all. Never mind (10) itself. Are there any other theorems or inferential patterns that depend on such a law? ${ }^{25}$ In the Metaphysics, Aristotle famously says that

all who are carrying out a demonstration refer to this as an ultimate belief; for it is naturally the starting-point even for all the other axioms. ${ }^{26}$

But this sounds more like a closing flourish than a precise assessment of the role of (10) in actual arguments, as when Leibniz says that everybody_even "barbarians"- must tacitly rely on it at every moment. ${ }^{27}$ In fact, the relevant section of the Posterior Analytics says explicitly that the law itself does not actually feature in the context of any interesting proof:

That it is not possible to affirm and deny [the same predicate of the same subject] at the same time is assumed by no demonstration-unless the conclusion too is to be proved in this form. ${ }^{28}$

The latter view became especially popular among medieval philosophers, not least through Aquinas's reading of it: Nulla demonstratio accipit hoc principium. ${ }^{29}$ So,

\footnotetext{
${ }^{25}$ This is - correctly, in my opinion-the starting point of Berto (2007), at p. 4.

${ }^{26}$ Metaphysics, IV.3 (1005b32-34); W. D. Ross's translation.

${ }^{27}$ New Essays, I. i.4.

${ }^{28}$ Posterior Analytics, I.11 (77a10-11); W. D. Ross's translation.

${ }^{29}$ Commentary on Aristotle's Posterior Analytics, I.1.xix.
} 
if that view is indeed correct, then one might as well say that the worry does not bite deep. The law of non-contradiction may be an entrenched dogma, but doing away with it needn't be a big deal.

The view, however, is not correct. For one thing, this is already apparent from the Square of Opposition, in the original form as well as in its modern, weaker variant. The very inference from a statement to the denial of its contradictory, as in (2) above, depends crucially on (10). For, as already mentioned, in a world where the A-form premise 'Every $S$ is $P$ ' is true, the existence of an $S$ that is both $P$ and not $P$ would warrant the truth of the corresponding $\mathbf{O}$-form statement 'Some $S$ is not $P$ ', hence the falsity of the conclusion in (2). Thus, exactly as with the move from Aristotelian logic to modern quantification theory with regard to the inference in (1), and the move from quantification theory to free logic with regard to the inference in (3), the move from any such theory to a logical theory that is not committed to the law of non-contradiction would require the inference in (2) to be revised by adding a further premise asserting the relevant instance of the law:

(2') Every $S$ is $P$.

Nothing is both $P$ and not $P$

$\therefore$ It is not the case that some $S$ is not $P$.

The same applies to other inferential patterns that make up that core of Aristotelian logic that has survived all the way to free logic, such as obversion (e.g., from the 'Every $S$ is $P$ ' to 'No $S$ is not $P$ '), exactly as some of those patters depend implicitly on the law of excluded middle (e.g., the inference from 'No $S$ is not $P$ ' back to 'Every $S$ is $P$ ').

Second, and more important, modern logic is characterized by several additional patterns of reasoning that rely implicitly on the law of non-contradiction, beginning with so called indirect proofs (also known, quite aptly, as "proofs by contradiction", though they depend just as much on excluded middle). The following inference is an obvious case in point:

(13) If $a$ is $S$, then $a$ is $P$.

If $a$ is $S$, then $a$ is not $P$

$\therefore a$ is not $S$.

It is indeed telling that precisely this sort of inference founders in most systems of paraconsistent logic. Another obvious example is the inferential pattern known as ex contradictione quodlibet, the rejection of which is a central feature of most systems of paraconsistent logic:

(14) Something is both $P$ and not $P$.

$\therefore a$ is $Q$. 
The validity of this inference, as of any inference from the same premise to any conclusion whatsoever, rests implicitly on the fact that the law of non-contradiction completely rules out any possibility for the premise to be true. And if there is no possible circumstance under which the premise is true, then a fortiori there is no possible circumstance under which the premise is true and the conclusion false.

Finally - though this is more controversial — a similar point could be made with regard to argument forms that do not, on the face of it, involve any explicit use of negation. Łukasiewicz remarked that such direct proofs do not in fact depend on the law of non-contradiction, since the law "always joins an affirmative proposition and its contradictory negative". ${ }^{30}$ But as some commentators have pointed out, what is presupposed by a pattern of inferential reasoning may not be part of that reasoning itself. ${ }^{31}$ Consider, for instance, the following argument:

(15) $a$ is $S$ and $b$ is either $P$ or $Q$.

$\therefore$ Either $a$ is $S$ and $b$ is $P$, or $a$ is $S$ and $b$ is $Q$.

On the face of it, this argument is valid, not only in standard quantification theory, but also in free logic - a mere instance of the distributivity of conjunction over disjunction. And surely enough, this is a direct argument whose validity does not require an appeal to (10) as an implicit premise. However, to the extent that the notion of validity is defined semantically in the spirit of the "locked room" metaphor-as the relation that holds between the premises of an argument and its conclusion if and only if there is no possible circumstance under which the former are true while the latter is false - one could reason as follows. Why is (15) valid? Answer: precisely because there is no circumstance under which its premise is true while the conclusion is false. But neither is there any circumstance under which the premise is false while the conclusion is true; the premise and the conclusion stand or fall together, i.e., they are equivalent, they are true exactly under the same circumstances. Thus, the answer boils down to this: (15) is valid because there is no possible circumstance under which the premise is true while the premise itself is false, which is to say, no possible circumstance under which the premise is both true and false. And isn't this just another way of saying that (15) is valid owing to contravelence, hence to the law of non-contradiction?

As I said, this third point is more controversial, among other reasons because it is not quite clear what exactly warrants the crucial central claim, to the effect that the premise and the conclusion are true under exactly the same circumstances.

\footnotetext{
${ }^{30}$ Łukasiewicz (1910b), p. 33.

${ }^{31}$ See e.g. Wedin (2000), at pp. $117 \mathrm{ff}$, though his examples are erroneous.
} 
But never mind. Even short of this last point, we have enough good reasons to conclude that there are theorems and inferential patterns that depend strictly on the law of non-contradiction, contrary to Aristotle's remarks in the second quote above. ${ }^{32}$ Hence, the worry on the table is not ill-grounded. On the contrary, forgoing the law is a big deal indeed, for so much depends on it. The discussion of (15), however, is also useful in relation to the other issue mentioned at the beginning of this section. For the reasoning offered in connection with (15) rests on the idea that there is an intimate link between the law of non-contradiction, as stated in (10), and the principle of contravalence, (12). It's easy to see that in the presence of the latter, the former admits of no counterexamples, so in this respect the reasoning is not fallacious. But I have already pointed out that contravalence is, strictly speaking, the profession of a semantic principle, the dual of bivalence. And just as it may be argued that the semantic principle of bivalence, understood as in (11), is not implied by the law of excluded middle, understood strictly as in (9), one can argue that the semantic principle of contravalence is not implied by the law of non-contradiction. Aristotle himself did not seem to see any significant difference, treating (10) and (12) as expressing the same fundamental idea ${ }^{33}$ (an attitude that is shared, more or less carelessly, by many contemporary philosophers and logicians ${ }^{34}$ ). Indeed, he helped himself with a third way of formulating what he thought was the same idea, namely, that "it is impossible for any one to believe the same thing to be and not to be". ${ }^{35}$ We can safely set this third formulation aside here, for there are good reasons to think that it pertains the realm of psychology rather than ontology proper, or semantics. ${ }^{36}$ But the relationship between (10) and

${ }^{32}$ For a full account of the role of the law in Aristotelian logic, see Cavini (2008).

${ }^{33}$ See e.g. Metaphysics, IV.3 (1005b19-20) and IV.6 (1011b13-14), respectively.

${ }^{34}$ Even authors who carefully draw the distinction between bivalence and excluded middle often conflate contravalence and non-contradiction; see e.g. Haack (1978), at pp. 246 and 246. In fact, there is still a pervasive tendency to conflate the former distinction, too. To give just one example, Copi's (1953) popular textbook survived all its fourteen editions, up to Copi and Cohen (2010), treating (9) and (11) as if they expressed one and the same doctrine. (See DeVidi and Solomon, 1999, for an assessment of this ubiquitous practice.) All of this over and above any differences in terminology, which in the case of (10) and (12) is especially striking: even authors who draw all the relevant distinctions tend to use 'law of non-contradiction' to refer to contravalence (otherwise known as biexclusion, or exclusion, or just as the dual of bivalence).

${ }^{35}$ Metaphysics, IV.3 (1005b23-25); W. D. Ross's translation.

${ }^{36}$ The three formulations were clearly distinguished for the first time by Łukasiewicz (1910a, 1910b), though he used the label "logical" for what I have called the "semantic" principle of contravalence - a terminology that is still current practice. 
the attendant semantic principle of contravalence, (12), is central to our present concerns. How does it work, exactly? And how does it play out in relation to the desideratum of an ontologically neutral logic?

\section{Contravalence and Contradiction}

I have already remarked that, in one direction, the relationship between the law of non-contradiction and the principle of contravalence is straightforward. If we have a counterexample to (10), say

(16) $a$ is both $P$ and not $P$,

then the following must hold:

(17) ' $a$ is both $P$ and not $P$ ' is true.

From this, it follows that each of the following must hold, too:

(18) ' $a$ is $P$ ' is true

(19) ' $a$ is not $P$ ' is true

But (19) is equivalent to

$\left(19^{\prime}\right)$ ' $a$ is $P$ ' is false.

Hence we can conclude that

(20) ' $a$ is $P$ ' is both true and false.

Thus, our putative counterexample to the logical law of non-contradiction turns automatically into a counterexample to the semantic principle of contravalence. And since nothing in our reasoning depends on the specific form of the counterexample, by generalization this means that the logical law is entailed by the semantic principle.

The converse entailment, however, need not stand. More precisely, if we ran the argument in reverse, i.e., from (20) to (16), our reasoning would be acceptable only under certain semantic assumptions which, in the present context, cannot be taken for granted. I am referring specifically to the semantic assumptions that govern the truth conditions of statements involving the logical operators - here, the connectives for negation, 'not', and for conjunction, 'and'. Standardly, the conditions for these connectives would be formulated as follows:

(21) 'Not $A$ ' is true if and only if ' $A$ ' is false.

(22) ' $A$ and $B$ ' is true if and only if ' $A$ ' and ' $B$ ' are true. 
Given these conditions, there is no question that the argument could be run symmetrically in either direction. Absent contravalence, however, the validity of the truth conditions for conjunction, (22), may be questioned: from left to right, the biconditional is irreproachable, warranting the inference from (17) to (18)-(19), ${ }^{37}$ but from right to left the biconditional may fail, thus blocking the inference in the reverse. Since to establish the entailment from non-contradiction to contravalence one cannot assume the latter at the start, it follows therefore that in that direction the entailment founders.

When exactly does (22) fail from right to left? It depends on the relevant motivations for rejecting contravalence. Suppose, for example, that our motivations for doing so stem from the desire to model the logic of a discussion group, as in Jaśkowski's "discursive logic". ${ }^{38}$ We want to say that a statement counts as true, in the context of a discussion, if and only if it is held true by at least one of the participants. Evidently, different participants in the discussion may disagree while being perfectly self-consistent. For instance, some may claim that $a$ is $P$ while others may claim that $a$ is not $P$, though no one will claim that $a$ is both $P$ and not $P$. In such a case, then, each of ' $a$ is $P$ ' and ' $a$ is not $P$ ' will be true, yet their conjunction will not. For another example, suppose that our motivations stem instead from the need to deal with a data bank compiled from different sources, or to explain how a useful data processor "should think", as Belnap put it. ${ }^{39}$ The data come from sources which, alas, may not always agree, though each one is on the whole trustworthy. If one source says that $A$ while another says the opposite, the data processor should treat both ' $A$ ' and 'not $A$ ' as true. Yet, again, as long as each of the sources is self-consistent, the processor should refrain from treating ' $A$ and not $A$ ' as also true. A third example comes from the need to "quarantine inconsistencies", as Lewis put it ${ }^{40}$ in the context of literary fiction. We have all read the Holmes stories and we know how to put them together. Truth in Holmes's world is truth according to at least one of the stories. Yet there are discrepancies. We are told that Dr. Watson suffered a bullet wound during the Afghan campaign in which he participated, but in A Study in Scarlet the wound is said to be located in Watson's shoulder, in The Sign of Four it is located in his leg. It would be logical cha-

${ }^{37} \mathrm{I}$ am of course assuming, here as elsewhere, that ' $a$ is both $P$ and not $P$ ' is shorthand for ' $a$ is $P$ and $a$ is not $P$ '.

${ }^{38}$ Jaśkowski (1948).

${ }^{39}$ Belnap (1977).

${ }^{40}$ See Lewis (1982), though the example that follows is from Lewis (1983). I am, in fact, just offering it as a simple example, with no intention to be dismissive of the complications discussed e.g. in Proudfoot (2006). 
os if we inferred that Watson's wound both is and isn't in his shoulder (and in his leg). But we don't, for once again we do not infer the truth of a conjunction from the truth of its conjuncts.

Of course, one might protest that none of these cases should be given much credit. That is, one might protest that a fictional story, a data bank, the record of a discussion, etc. do not constitute good examples of the sort of possible "circumstance" under which a statement can properly be said to be true or false in the sense that matters when it comes to reasoning in the logician's locked room; there are other ways to address the relevant needs. For example, one could resort to a suitable sentential operator that maps every statement $A$ to a corresponding statement of the form

\section{(23) According to $\Phi: A$}

where $\Phi$ is the story in question, the computer's data bank, the record of a discussion, or what have you. Then the cases discussed above would provide us with good reasons to question the following biconditional:

(24) 'According to $\Phi: A$ and $B$ ' is true if and only if 'According to $\Phi: A$ ' and 'According to $\Phi: B$ ' are true.

But this would have no bearing on the status of (22). 'According to $\Phi$ ' is an operator that may introduce an intensional context, on a par with 'Possibly', or 'Graham said that', and the question of whether such intensional contexts distribute over conjunction should be kept distinct from the question of whether conjunction itself is properly governed by the truth conditions in (22). In fact, that question has no bearing on whether contravalence holds, either, for obviously a statement of the form (23) and a statement of the form

(25) According to $\Phi: \operatorname{not} A$

do not contradict each other; they simply attest to the self-contradictoriness of $\Phi$ (just as the statements

(26) Graham said that $A$

(27) Graham said that not $A$

do not contradict each other but rather attest to the contradictoriness of Graham's pronouncements).

There is indeed nothing wrong with this line of thought, except that it misses the point. For the issue on the table is the relationship between the principle of contravalence and the law of non-contradiction, specifically whether the former is 
entailed by the latter. We may find good ways of dealing with the three cases mentioned above (and similar ones) so as to preserve (22) along with contravalence, and the use of a suitable sentential operator may well be one of them. ${ }^{41}$ In that case, the entailment would be safe and we might conclude that contravalence and noncontradiction stand or fall together. This is not an unpopular view, equally available to the friends and foes of the law of non-contradiction. But to the extent that any of those cases counts as a legitimate motivation for rejecting contravalence, to that extent we have reasons to deny the entailment and, with it, the equivalence between contravalence and non-contradiction. Since it is a fact that a variety of logical theories have been developed that violate contravalence precisely on such grounds, a dismissive attitude would not, in the present context, be of service.

Besides, the very question of what constitutes a good example of the notion of "circumstance" that is relevant to the concepts of logical truth and logical validity is part of the problem. Obviously, to rule out certain options just because they would infringe contravalence would beg the question. It might be fine to insist on the use of a suitable sentential operator, as in (23). But then, again, nothing prevents us from doing the same when ' $\Phi$ ' stands for a possible world of the garden variety. In that case, 'According to $\Phi$ ' would presumably be redundant, which is to say that the following biconditional would hold

[According to $\Phi: A$ ] if and only if $A$.

and (24) would reduce to (22). But so be it. The question is precisely whether there are any other candidates for ' $\Phi$ ' that behave in the same way. There is no obvious a priori reason why the logician in the locked room should answer this question in the negative.

Finally, even if we kept to the idea that the only admissible "circumstances" are genuine worlds of sorts (as opposed to the "ersatz worlds" that emerge from fictional stories, data banks, etc.), the argument for (22) can hardly be that truth commutes with the truth-functional connectives. ${ }^{42}$ That is, that can hardly be the argument as soon as we entertain the possibility that a genuine world may be the source of counterexamples to such semantic principles as bivalence and contravalence. If that were the case, then the rationale for (22) would also be a rationale for

${ }^{41}$ Thus, for example, Jaśkowski's discursive logic can be embedded into modal logic through the familiar Kripkean modalities. See da Costa and Dubikajtis (1977). For a general overview of this strategy, see Arló Costa (2005).

${ }^{42}$ That is how Lewis (1986), p. 7n, draws the line. What follows draws on my response in Varzi (1997). 
'Not $A$ ' is true if and only if ' $A$ ' is not true.

Yet clearly (29) is controversial. In classical logic, 'not true' just means 'false', so (29) is equivalent to the condition given in (21). But as soon as we allow for the possibility of sentences that are neither true nor false, or both true and false, (29) is stronger than (21). On most counts, if ' $A$ ' is neither true nor false, then so is its negation, hence the right-to-left direction of (29) may fail. And if ' $A$ ' is both true and false, then it is the left-to-right direction of (29) that fails. Thus, on most theories, truth does not commute with negation. Why should conjunction behave any differently? Why should (22) fare any better when we leave the terra firma of classical logic? As it turns out, failure of bivalence is harmless in this respect. ${ }^{43}$ Failure of contravalence need not be, at least with respect to the right-to-left direction of (22). Why should this departure be regarded as a violence to the "normal interpretation" of the logical connectives? ${ }^{44}$

\section{Genuine Contradictions?}

I hope this will suffice to establish the main point so far: while there is a straightforward argument from the principle of contravalence to the law of non-contradiction, i.e., from

(12) No statement is both true and false,

to any instance of

(10) Nothing is both $P$ and not $P$.

the argument in the opposite direction is wanting. Indeed, it is worth noting that precisely the same sort of consideration may be called upon to motivate the parallel claim mentioned earlier in connection with bivalence and excluded middle, namely, that while the former,

(11) Every statement is either true or false,

entails all instances the latter,

(9) Everything is either $P$ or not $P$,

${ }^{43}$ Of course, absent bivalence it becomes necessary to supplement (22) with necessary and sufficient conditions for a conjunction to be false. In itself, however, (22) stands.

${ }^{44}$ See Priest and Routley (1989b), n. 159, where the departure is compared to that of intuitionistic negation. 
the converse entailment need not hold. One can reason from, say, the denial of (30) $a$ is either $P$ or not $P$.

to the denial of

(31) ' $a$ is $P$ ' is either true or false.

in a way that is perfectly dual to the foregoing argument from the acceptance of (16) to the acceptance of (20), this time using the right-to-left direction of the standard truth conditions for the disjunction connective, 'or':

(32) ' $A$ or $B$ ' is true if and only if ' $A$ ' or ' $B$ ' is true.

That is a perfectly legitimate way of reasoning. But running the argument in reverse, from the falsity of (31) to the falsity of (30), would call for the left-to-right direction of (32), and inspection shows that in that direction (32) fails in each of the three cases considered above-Jaśkowski's discursive logic, Belnap's computer logic, or Lewis's logic of fiction. That is why I said that failure of bivalence need not entail genuine ontological indeterminacy, i.e., genuine counterexamples to excluded middle. ${ }^{45}$ Likewise, the present point is that failure of contravalence need not entail genuine ontological overdeterminacy, i.e., genuine counterexamples to non-contradiction.

Our question then comes to this: When is the inference legitimate, if ever? Under what conditions can we warrantably say that a dialetheia - a statement that is both true and false - is bona fide evidence of a contradiction arising in the world? After all, typically the only evidence we can rely on, in logic as elsewhere in philosophy, comes in the form of claims or intuitions to the effect that certain statements are true and others are false. But as I remarked before, this is slippery business. The fallacy of verbalism - the fallacy of mistaking facts about words for facts about worlds - is constantly lurking. Is there any way of detecting it when it comes to assessing putative infringements of logical laws? Specifically, is there any way of discriminating a merely de dicto dialetheia from a genuinely de re one? In my opinion, that is the best question we can ask if we are interested in the status of the law of non-contradiction vis-à-vis the desideratum of the ontological neutrality of logic.

Alas, I do not have a clear and distinct answer to offer. But I do have two suggestions that, hopefully, will at least be indicative of the kind of answer that I think we should seek. Both are probably too loaded, philosophically, to be of much

\footnotetext{
${ }^{45}$ In essence, this is my reply to Williamson's argument mentioned in $\mathrm{n} .15$ above.
} 
service. And both come with reservations, the most important of which is that in some cases they yield the wrong verdict. Let me try to outline them none the less.

\section{First Suggestion}

The first suggestion builds directly on the foregoing. To the extent that a counterexample to contravalence results in a violation of the law of non-contradiction only insofar as it can be conjoined with its own negation to yield a single, explicit statement of the form

(16) $a$ is both $P$ and not $P$,

we can say that it counts as bona fide evidence of a contradiction arising in the world if, and only if, the logical theory assumed in the background licenses such a move. Pretty clearly, a sufficient condition for that to be the case is that the theory validate the relevant instances of conjunction introduction:

(33) $\quad a$ is $P$

$a$ is not $P$

$\therefore a$ is both $P$ and not $P$.

And we have seen that such a move need not be valid insofar as the semantic behavior of 'and' may run afoul of the standard truth conditions, (22). Thus, the suggestion is simply to look at the whole picture, which is to say the whole set of axioms and inferential patterns that define the logic whose neutrality we are trying to assess. After all, the meaning of a statement is at least in part determined by its logical relations to other statements, hence it is only the network of such relations that can help us answer our question. And when it comes to contradictions, the crucial relation is the one reflected in (33).

A different way of putting the same point is this. There are two ways of construing the notion of a contradiction. The first is the one we have been using throughout, the "collective" sense, according to which a contradiction manifests itself in the form of a single statement, as the joint assertion of a proposition and its denial. The other is the "distributive" sense, according to which a contradiction arises whenever someone asserts something she is also denying, whether or not she does both things "in the same breath" (as Strawson used to put it ${ }^{46}$ ). Both notions are perfectly legitimate. But it is only a contradiction in the strong, collective sense

${ }^{46}$ Strawson (1952), ch. 1, passim. For further details on the distinction between collective and distributive construals of the notion of a contradiction, see Varzi (2004). 
that bears witness to a circumstance in which things infringe of the law. At least, this is the suggestion I am offering:

(S1) A contradiction is de re if and only if it is closed under conjunction.

Contradictions that arise only in the distributive sense-contradictions that don't conjoin — are merely evidence of discrepancies in our ways of talking about things, as with Sir Arthur's slips of the pen. That's why they do not imply logical chaos. Absent (33), the law of non-contradiction may still warrant the "explosive" inferential pattern in (14), ex contradictione quodlibet. It need not, however, warrant its distributive variant:

$\left(14^{\prime}\right) \quad a$ is $P$

$a$ is not $P$

$\therefore a$ is $Q$

If this account is accepted, then we can draw our first moral. Our initial question was whether the law of non-contradiction reflects an ontological prejudice that should not be built into our logic. We now see that it need not be so unless we endorse (33). Since classical logics (including free logic) warrant (33) unrestrictedly, it follows that something has to give. One way or the other, a paraconsistent logic has better claim to ontological neutrality. ${ }^{47}$ Unfortunately, there is an obvious problem with the account, which is why I said it is just a "suggestion". That is, there is an obvious problem over and above the fact that one may just not agree with the idea that distributive contradictions fall short of biting at the ontological level. ${ }^{48}$ A simple example will suffice. Suppose the predicate ' $P$ ' was introduced, by definition, in a way that is not quite coherent: we stipulated that, say, ' $P$ ' is true of every individual who is at least 16 years old, and false of every individual who is less than 18 years old. Clearly, both ' $a$ is $P$ ' and ' $a$ is not $\mathrm{P}$ ' will turn out to be true when ' $a$ ' picks out an individual whose age is between 16 and 18. But suppose now that our logic does license the inference in (33) by conjunction introduction (as in many systems of paraconsistent logic). It follows that we can derive a genuine counterexample to the law of non-contradiction, and (S1) would confirm that the contradiction in question is genuinely de re. But that is

${ }^{47}$ For the record, paraconsistent logics in which (33) does not hold are generally known as non-adjunctive. As it turns out, Jaśkowski's discursive logic was the first of the kind. For a brief survey of other non-adjunctive logics, see e.g. Priest (2002), §4.2.

${ }^{48}$ For example, Rescher and Brandom's (1980) "logic of inconsistency" is nonadjunctive precisely in the sense described here. Yet they are adamant about distributive contradictions being grounded in the world itself, not just our discourse about it. 
ludicrous. Why should the world be blamed for the sloppiness of our linguistic stipulations? Even a hard-core dialetheist such as Priest would resist that conclusion. $^{49}$

Of course, one could respond that this sort of case provides further evidence against conjunction introduction. But this is a familiar predicament that leads nowhere: one philosopher's modus ponens is another philosopher's modus tollens. That is why I said that the suggestion on the table is too loaded, philosophically, to be of much service when it comes to applying it to actual cases. We are still missing some independent criteria for saying whether the truth conditions of a given statement suffer from our contradictory semantic practices. We need necessary and sufficient conditions for determining whether ' $a$ is $P$ ' is supposed to violate contravalence because of the meaning of ' $a$ ' and ' $P$ ' or because of how $a$ and $P$ are. Absent such criteria, we have an account that cries for guidelines.

\section{Second Suggestion}

It is here that the second suggestion enters the picture. And it is a suggestion that builds once again on the duality between non-contradiction vs. contravalence, on the one hand, and excluded middle vs. bivalence, on the other. As it turns out, in connection with the latter opposition there has been a conspicuous debate concerning precisely the dual of our question - namely, under what conditions can we warrantably say whether a statement being neither true nor false is bona fide evidence of an indeterminacy arising in the world? Precisely because of Russell's influential attempt to discredit all putative ontological vagueness as a form of verbalism, several efforts have been made to explicitly address this question in its general form, at least with respect to certain varieties of indeterminacy such as indeterminacy due to vagueness. And such efforts have often included an account of what it is for an expression to lack a definite, fully determinate meaning-exactly the dual of what we are missing. The suggestion, then, is to capitalize on such efforts; to "piggy back" on what I take to be the best account that arose out of them and "dualize" it.

Before explaining how that works, let me briefly illustrate with a concrete example the force of the duality between the two cases. Suppose someone says that the statement

(34) Tibbles is white.

${ }^{49}$ See Priest $(201+)$ for an explicit statement to that effect. 
is neither true nor false. This flies in the face of bivalence. Does it mean that we have a (purported) counterexample to excluded middle? It depends on the semantic theory assumed in the background. If we assume that the name 'Tibbles' picks out a unique individual, the cat Tibbles, and the predicate 'white' picks out a unique property, the color white (or whatever sort of entity we take the semantic value of our predicate to be-e.g., a class of individuals), then the answer is in the affirmative: we are told that it is a fact of the matter, a matter of how things are in the world, that Tibbles neither definitely is nor definitely isn't white. On the other hand, one might resist that semantic assumption and maintain instead that the name 'Tibbles' fails to pick out a unique individual, or that the predicate 'white' fails to pick out a unique color. There are many (slightly different) cat-like individuals and many (slightly different) white-like colors out there, one for each admissible way of "sharpening" the reference of 'Tibbles' and the reference of 'white', and each of those individuals either definitely has or definitely fails to have each of those colors. If our statement turned out to be true under every such sharpening, then we could say that the statement is true. If it turned out to be false under every sharpening, then we could say that the statement is false. But if, as we may suppose, the truth value of our statement changes depending on which sharpening we consider, then there's no way for us to settle the issue. No sharpening is better than the others, hence neither truth value will trump the other. That is why (34) lacks a truth value altogether, yielding a counterexample to bivalence. ${ }^{50}$ But the answer to our question is in the negative. For note that a statement such as

Tibbles is either white or not white.

would come out true under every sharpening, since every sharpening will verify one disjunct or the other. The law of excluded middle still holds.

This is perfectly parallel to the case we are interested in, where someone might say that (34) is both true and false. If we assume that 'Tibbles' and 'white' have a perfectly coherent semantic connotation, then the claim in question is warranted if, and only if, it is a fact of the matter that Tibbles both is and is not white - a genuine violation of the law of non-contradiction. But one might also contend that it is just the word 'Tibbles', or perhaps the word 'white', that comes with a contradictory interpretation. There are several ways of clearing up the interpretation of these words, each corresponding to a (slightly different) way of extracting a genuine semantic value from their incoherent semantic behavior: a genuine individual as the referent of 'Tibbles' and a genuine color property as the value

${ }^{50}$ This is the gist of the supervaluationist account mentioned in $\mathrm{n} .14$ above. 
of 'white'. Since each way of doing so is as legitimate as the others, each will warrant a legitimate truth-value assignment to (34), and since each of those individuals turns out to possess one of those properties while failing to possess the others, (34) turns out to be both true and false, yielding a counterexample to contravalence. However, note that a statement such as

(36) Tibbles is both white and not white.

would come out false and only false in each case, since every coherent interpretation of 'Tibbles' and 'white' will falsify one conjunct or the other. Hence the law of non-contradiction still holds. ${ }^{51}$

So how can we tell? How can we say whether our interlocutor's claim should be interpreted in accordance with a definite and coherent semantics that speaks to an indeterminate and/or contradictory world, or in accordance with a semantics that is indefinite and/or incoherent, not because of the way things are in the world, but because of deficient stipulations? There is, I'm afraid, no way of telling just by looking at the statement in question. Nor would it be of any help to just ask our interlocutor what kind of semantics she has in mind, for that would leave everything up for grabs. However, we can once again rely on the fact that the meaning of an expression is determined, at least in part, by its logical behavior, hence by the network of logical relations that tie those statements in which the expression occurs, and we can try to answer our question by looking at how the claim at issue fits the rest of our interlocutor's logic.

Now, in the first case - where the claim is that (34) is neither true nor falseit seems to me that there is a good account available for this purpose. The basic idea grew out of the extensive debate triggered by Evans's argument against vague objects, especially through Lewis's revisitation of it,${ }^{52}$ but it is independent of that argument and admits of a general formulation. It can be put thus:

(S) An expression ' $e$ ' has a definite meaning if and only if ' $e$ ' admits of scope raising in contexts of the form 'it is indeterminate whether ...'.

where by "scope raising" I mean, quite generally, the move from a statement in which the expression in question has narrow scope with respect to a certain operator to a statement in which it has wide scope - thus, in particular, the inferential move in an argument of the form

${ }^{51}$ This "dualization" of supervaluationism is examined in detail in some of my earlier works, especially Varzi (1999, 2000).

${ }^{52}$ See Evans (1978) and Lewis (1988), respectively. 
(37) It is indeterminate whether $\ldots e \ldots$

$\therefore e$ is such that it is indeterminate whether ... it ...

Here is why ( $\mathrm{S})$ is a good account. If the expression ' $e$ ' lacks a definite meaning, then clearly the inference in (37) is fallacious. For whereas the premise can be true insofar as ' $e$ ' may admit of alternative sharpenings that do not settle the truth-value of ' $. . e . .$. ', precisely the variety of such sharpenings will prevent the conclusion from being true. Thus, to return to our example, and setting aside the nuances of the grammatical etiquette of English, if (34) is neither true nor false owing to some indefiniteness in the meaning of the name 'Tibbles', or of the predicate 'white', then the following arguments (respectively) are not truth-preserving, hence invalid:

(38) It is indeterminate whether Tibbles is white.

$\therefore$ Tibbles is such that it is indeterminate whether it is white.

(39) It is indeterminate whether Tibbles is white.

$\therefore$ White is such that it is indeterminate whether Tibbles is $i t$.

In this sense, the alternative sharpenings that come with an expression whose meaning is not fully specified play a role analogous to the alternative worlds of modal logic, 'indeterminate' being the analogue of 'contingent', and the invalidity of (38) and (39) is analogous to the invalidity of, say

(40) It is contingent whether the number of planets is greater than 7.

$\therefore$ The number of planets is such that it is contingent whether it is greater than 7 .

(41) It is contingent whether 7 is less than the number of planets.

$\therefore$ Less than the number of planets is such that it is contingent whether 7 is it.

However, if ' $e$ ' is not a semantically deficient expression-if it definitely picks out a unique individual, a unique property, etc. - - then the inference in (37) is perfectly legitimate. For in that case ' $e$ ' behaves like a rigid designator across any sharpenings that may still be necessary to evaluate '...e ...'. Indeed, when 'Tibbles' and 'white' are taken to have a definite meaning, (38) and (39) are just as valid as

(42) It is contingent whether 7 is less than the number of planets.

$\therefore 7$ is such that it is contingent whether it is less than the number of planets.

(43) It is contingent whether the number of planets is greater than 7.

$\therefore$ Greater than 7 is such that it is contingent whether the number of planets is it.

So why is (S) a good account? Because it pinpoints a crucial inferential pattern with respect to which the logical behavior of a well-defined expression and the logical behavior of an indefinite expression part company. Insofar as our prob- 
lem was to identify such a pattern, (S) does the job. And insofar as any claim to the effect that a statement $A$ is neither true nor false warrants a corresponding claim of the form

(44) It is indeterminate whether $A$,

the pattern in question is central enough for $(\mathrm{S})$ to count as useful in relation to the general question of determining the conditions under which failure of bivalence entails failure of the law of excluded middle. As with the distinction between collective and distributive readings of a contradiction, the entailment holds to the extent that we are willing to buy into a certain pattern of reasoning.

Let us, then, return to the case we are interested in, where the general question concerns instead the conditions under which failure of contravalence entails failure of the law of non-contradiction. I have already said that the two cases are fundamentally parallel — or rather, dual. And I take it that the duality extends to the point of saying that any claim to the effect that a statement $A$ is both true and false warrants a corresponding claim of the form

(45) It is overdeterminate whether $A$

My suggestion, then, is simply to exploit the duality all the way and dualize the account in $(\mathrm{S})$ to fit the case:

(S2) An expression ' $e$ ' has a coherent meaning if and only if ' $e$ ' admits of scope raising in contexts of the form 'it is overdeterminate whether ...'.

\section{Concluding Remarks}

Does (S2) do the job? Unfortunately, it is once again only a suggestion-and a tentative one at that. For there are at least two important respects in which (S2) is still deficient.

The first is that it hinges on shaky philosophical assumptions. In particular, it might be objected that it rests too heavily on contentious doctrines about reference. This is already apparent with (S). If, for example, one holds that every singular term has its reference fixed by descriptive means that invoke a sortal, and that all sortals are somewhat indefinite in meaning, then no singular term will have a definite meaning in the relevant sense. Hence, our strategy will imply that there are no good reasons to posit indeterminate objects - a conclusion that can hardly be justified on such grounds. ${ }^{53}$ Indeed, the whole idea of deriving ontic indeterminacy

\footnotetext{
${ }^{53}$ This point draws on Sainsbury (1989), pp. 99-100, mutatis mutandis.
} 
from violations of bivalence that do not involve indefinite language is in jeopardy, for it may leave us with no genuine ontic indeterminacy just because of widespread linguistic indeterminacy. This problem, and any variant thereof, are imported into (S2) holus bolus.

The second respect in which reference to (S2) won't take care of the problem in its generality is that failure of contravalence may come in the form of a statement that contains both expressions with a coherent meaning and expressions whose meaning has not been fixed in a coherent way. Accordingly, while (S2) itself provides both necessary and sufficient conditions for telling such expressions apart, knowing that a dialetheia involves expressions of the former sort may be necessary but not sufficient for classifying it as a sign of a genuine de re contradiction, just as knowing that it contains expressions of the latter sort may be insufficient for classifying it as a mere de dicto discrepancy. For instance, suppose that ' $P$ ' turns out to be an incoherent predicate, and suppose someone holds that

(46) The round square is $P$

is both true and false. Insofar as both 'round' and 'square' are perfectly coherent predicates, (S2) would license the inference

(47) It is overdeterminate whether the round square is $P$.

$\therefore$ The round square is such that it is overdeterminate whether it is $P$.

Yet it is far from obvious that this should count as evidence of a contradiction arising in the world. The round square may be an excellent candidate for the real content of Sylvan's box ${ }^{54}$ - a genuine, authentic, truly contradictory object. But the overdeterminacy of (46) may have nothing to do with this. It may still be a mere dialetheia ex vi terminorum due entirely to the incoherence of ' $P$ '.

I'm afraid I don't have much to offer in response to these concerns. As with (S1), (S2) turns out to be philosophically loaded, and prone to misjudgment. I wish I could say that while neither account does the job properly, both of them (collectively) do. But that is just not true. Let me simply say that in spite of the limits and defects of each, I hope that (S1) and (S2) provide at least a rough indication of the kind of criterion that I think is required in order to address the difficult question that has been the main concern of this paper, namely, whether the law of noncontradiction is yet another instance of the sort of prejudices from which logic has tried to free itself throughout its history in the spirit of ever greater ontological neutrality. The answer to that question may well be in the negative, since any evi-

\footnotetext{
${ }^{54}$ See Priest (1997).
} 
dence against the law may require that we deploy further principles to make the case, and it is those principles that may be deemed inadequate as canons of pure logical reasoning. Precisely for this reason, however, there seems to be no option short of confessing our narrow ontological horizons: something - if not the law, one of those principles - has gotta give. ${ }^{55}$

\section{References}

Arló-Costa, H., 2005, 'Non-Adjunctive Inference and Classical Modalities', Journal of Philosophical Logic 34: 581-605.

Asenjo, F. G., 1966, 'A Calculus of Antinomies', Notre Dame Journal of Formal Logic 7: 103-105.

Belnap, N. D. , Jr, 1977, 'How a Computer Should Think', in G. Ryle (ed.), Contemporary Aspects of Philosophy, Stocksfield: Oriel Press, pp. 30-55.

Bencivenga, E., 1986, 'Free Logics', in D. Gabbay and F. Guenthner (eds.), Handbook of Philosophical Logic, Vol. 3, Dordrecht: Reidel, pp. 373-426.

- 1999, 'What Is Logic About?', in A. C. Varzi (ed.), The Nature Of Logic (European Review of Philosophy, Vol. 4), Stanford: CSLI Publications, pp. 5-19.

Berto, F., 2007, How to Sell a Contradiction. The Logic and Metaphysics of Inconsisten$c y$, London: College Publications.

Cavini, W., 2008, 'Principia contradictionis. Sui principi aristotelici della contraddizione (§4)', Antiqvorvm Philosophia 2: 159-187.

Church, A., 1965, 'The History of the Question of Existential Import of Categorical Propositions,' in Y. Bar-Hillel (ed.), Logic, Methodology, and Philosophy of Science: Proceedings of the 1964 International Congress, Amsterdam: North-Holland, pp. 417-424.

Copi, I., 1954, Introduction to Logic, London: MacMillan.

Copi, I., and Cohen, C., 2010, Introduction to Logic, 14th edition, Upper Saddle River, NJ: Prentice-Hall.

da Costa, N. C. A., 1974, 'On the Theory of Inconsistent Formal Systems', Notre Dame Journal of Formal Logic 15: 497-510.

da Costa, N. C. A., and Dubikajtis, L., 1977, 'On Jaśkowski’s Discussive Logic', in A. I. Arruda, N. C. A. da Costa, and R. Chuaqui (eds.), Non-Classical Logics, Model Theory, and Computability, Amsterdam: North-Holland, pp. 37-56.

DeVidi, D., and Solomon, G., 1999, 'On Confusions About Bivalence and Excluded Middle', Dialogue 38: 785-799.

Evans, G., 1978, 'Can There Be Vague Objects?', Analysis 38: 208.

${ }^{55}$ Many thanks to Wolfgang Mann, Walter Cavini, and all the participants at the Berlin conference on Contradictions: Logic, History, Actuality (June 3, 2011) for their valuable feedback on earlier versions of this paper. 
Fine, K., 1975, 'Vagueness, Truth and Logic', Synthese 54: 235-59.

Frege, G., 1893/1903, Grundgesetze der Arithmetik, begriffsschriftlich abgeleitet (2 vols.), Jena: Pohle.

Gödel, K., 1944, 'Russell's Mathematical Logic', in P. A. Schlipp (ed.), The Philosophy of Bertrand Russell, Evanston: The Library of Living Philosophers, pp. 125-153.

Haack, S., 1978, Philosophy of Logics, Cambridge: Cambridge University Press.

Hintikka, J., 1959, 'Existential Presuppositions and Existential Commitments', Journal of Philosophy 56: 125-137.

Hyde, D., 2008, Vagueness, Logic and Ontology, Aldershot: Ashgate.

Jaśkowski, S., 1934, 'On the Rules of Supposition in Formal Logic', Studia Logica 1: 5-32.

- 1948, 'Rachunek zdań dla systemów dedukcyjnych sprzecznych', Studia Societatis Scientiarun Torunesis, Sectio A, 1/5: 55-77.

Kneale, W. and Kneale, M., 1962, The Development of Logic, Oxford: Oxford University Press.

Lambert, K., 1967, 'Free Logic and the Concept of Existence', Notre Dame Journal of Formal Logic 8: 133-144

Lehman, S., 2002, 'More Free Logic', in D. Gabbay and F. Guenthner (eds.), Handbook of Philosophical Logic, $2^{\text {nd }}$ edition, Vol. 5, Dordrecht: Kluwer, pp. 197-259.

Leonard, H. S., 1956, 'The Logic of Existence', Philosophical Studies 7: 49-64.

Lewis, D. K., 1982, 'Logic for Equivocators', Noûs 16: 431-41.

- 1983, 'Postscripts to "Truth in Fiction"', in his Philosophical Papers, Volume I, New York: Oxford University Press, pp. 276-80.

- 1986, On the Plurality of Worlds, Oxford: Blackwell.

— 1988, 'Vague Identity: Evans Misunderstood', Analysis 48: 128-130.

Łukasiewicz, J., 1910a, O zasadzie sprzeczności u Arystotelesa: Studyum krytyczne, Kraków: Akademia Umiejętności.

- 1910b, 'Über den Satz des Widerspruchs bei Aristoteles', Bulletin international de l'Académie des sciences de Cracovie, Classe d'histoire et de philosophie, 1/2: 15-38.

Pelletier, F. J., 1989, 'Another Argument Against Vague Objects', Journal of Philosophy 86: 481-492.

Priest, G., 1979, 'Logic of Paradox', Journal of Philosophical Logic 8: 219-241.

- 1987, In Contradiction: A Study of the Transconsistent, Dordrecht: Nijhoff [2nd expanded edition: Oxford: Oxford University Press, 2006].

- 1995, Beyond the Limits of Thought, Cambridge: Cambridge University Press, 1995 [2nd expanded edition: Oxford: Oxford University Press, 2001].

— 1997, 'Sylvan's Box: A Short Story and Ten Morals', Notre Dame Journal of Formal Logic 38: 573-582.

— 1998, 'What Is So Bad About Contradictions?', Journal of Philosophy 95: 410-426.

- 2002, 'Paraconsistent Logic', in D. Gabbay and F. Guenthner (eds.), Handbook of Philosophical Logic, $2^{\text {nd }}$ edition, Vol. 6, Dordrecht: Kluwer, pp. 287-393.

- 201+, 'Contradictory Concepts', forthcoming in J. Meheus, E. Weber, and D. Wouters (eds.), Logic, Reasoning and Rationality, Berlin: Springer.

Priest, G., and Routley, R., 1989a, 'Introduction', in G. Priest, R. Routley, and J. Norman 
(eds.), Paraconsistent Logic: Essays on the Inconsistent, Munich: Philosophia, pp. ixx-xxi.

- 1989b, 'First Historical Introduction. A Preliminary History of Paraconsistent and Dialectic Approaches', in G. Priest, R. Routley, and J. Norman (eds.), Paraconsistent Logic: Essays on the Inconsistent, Munich: Philosophia, pp. 3-75.

Proudfoot, D., 2006, 'Possible Worlds Semantics and Fiction', Journal of Philosophical Logic 35: 9-40.

Quine, W. V. O., 1948, 'On What There Is', Review of Metaphysics 2: 21-38.

Rescher, N., and Brandom, R., 1980, The Logic of Inconsistency. A Study in Non-Standard Possible-World Semantics and Ontology, Oxford: Basil Blackwell.

Russell, B., 1905, 'On Denoting', Mind 14: 479-493.

- 1919a, Introduction to Mathematical Philosophy, London: Allen and Unwin.

— 1919b, 'The Philosophy of Logical Atomism' [Parts V-VI], The Monist 29: 190-222.

— 1923, 'Vagueness', Australasian Journal of Philosophy and Psychology 1: 84-92.

Sainsbury, R. M., 1989, 'What Is a Vague Object?', Analysis 49: 99-103.

Salmon, N., 1982, Reference and Essence, Oxford: Blackwell.

Strawson, P. F., 1952, Introduction to Logical Theory, London: Methuen.

Varzi, A. C., 1997, 'Inconsistency without Contradiction', Notre Dame Journal of Formal Logic 38: 621-638.

- 1999, An Essay in Universal Semantics, Dordrecht: Kluwer.

- 2000, 'Supervaluationism and Paraconsistency', in D. Batens, C. Mortensen, G. Priest, and J. P. Van Bendegem (eds.), Frontiers of Paraconsistent Logic, Baldock: Research Studies Press, pp. 279-297.

- 2001, 'Vagueness, Logic, and Ontology', The Dialogue 1: 135-154.

- 2004, 'Conjunction and Contradiction', in G. Priest, JC Beall, and B. Armour-Garb, (eds.), The Law of Non-Contradiction: New Philosophical Essays, Oxford: Clarendon Press, pp. 93-110.

Vasil'év, N. A., 1912, 'Logica i Métalogica', Logos 1-2: 53-81.

Wedin, M. V., 1990, 'Negation and Quantification in Aristotle', History and Philosophy of Logic 11: 131-150.

- 2000, 'Some Logical Problems in Metaphysics Gamma', Oxford Studies in Ancient Philosophy 19: 113-162.

Whitehead, A. N., and Russell, B., 1910/1913, Principia Mathematica (3 vols.), London: Cambridge University Press.

Williams, J. R. G., 2008, 'Ontic Vagueness and Metaphysical Indeterminacy', Philosophy Compass 3: 763-788.

Williamson, T., 1992, 'Vagueness and Ignorance', Proceedings of the Aristotelian Society 66 (Suppl.): 145-162. 